\title{
札幌市及びその近接地域の淡水産 プラナリアの生態調查報告
}

(括図 1 1 2)

\author{
山田達也・川勝 正治
}

\section{Report on the ecological survey of freshwater planarians in Sapporo City and its adjacent district, Hokkaidô By Tatsuya Yamada and Masaharu Kawakatsu}

札爆市とその近接地域の淡水㜀三肢腸類相は，北海道内では最も早くから調查された。 すなわ方，飯島鬼博上が 1913 年に，北海道大学構内の流れから Polycelis (=Sorocelis) sapporo（IJIMA et K KBURAKI，1916）を採集されたのに始まり，以後，北大関係の実験形 態学者や渦虫類学者によつて材料の採集や分類学的な調查が進められてきた。特に，1950 年以降注市川純彦教授が渦虫類の再生と分類の研究を始められ，また著者のひとり川腾が 共同研究者として生態, 分類, 分布学的な研究を始めたので, 当地域の三岐腸類相怯急速 に明らかとなつた。しかし，札坭市を中心とする地域の三岐腸類の分布に関导るまとまつ た調查注行なわれていなかつたので，著者らは1965 年夏に豊平川水系の謂查を実施した。

本稿をまとめるにあたり，著者らの矿究に対して常に援助と助言を与えられる北海道大 学理学部動物学教室の市川純彦教授と, 原稿を読えで御批判いただいた奈良女子大学理学 部動物学教室の津田松苗教授に深謝する。

\section{調查地域及び方法}

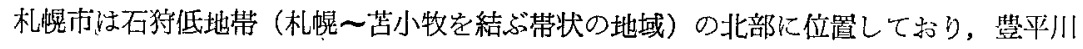
（石狩川の一支流）が市街地を貫流している。旧市内地域で法，今年度の調查データ以外 に従来から知られていた棲息地を整理して記述した。近郊地域は豊平川水系の中〜上流部 の支流一一厚别川，真駒内川 (空沼岳)，薄别川 (中山婥)，小川 (無意根山)，白井川，

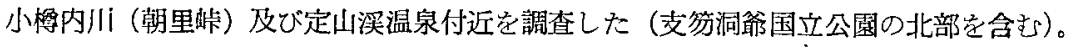
これらの地域のう方, 無意根山は 1965 年 7 月 10 日 11 日調查し, その他は同 8 月 10 日〜13日に調査した。

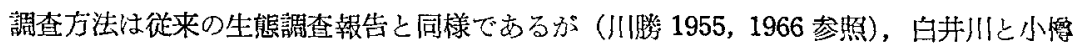
内川では主な地点の調查だけに止めた。 


\section{調 查 綪 果}

全調焦地域から得られた淡水棲三岐腸類は，下記の 7 種類である。

Planariidae 科: ナミウズムシ Dugesia japonica ICHIKAWA et KAWAKATSO, ミヤマウ ズムシ Phagocata vivida (IJIMA et KABURAKI), Phagocata iwamai ICHIKaWA et Kawakatsu, キタシロカズメウズムシ Polycelis sapporo (IJIMA et KaBURAKI)，カズメ りズムシ Polycelis auriculata I⿰IMA et $\mathrm{K}_{\text {ABURAKI }}$ デンドロシーラ科：キタシロウズ ムシ Dendrocoelopsis lacteus ICHIKAWA et OKUGAWA, エゾウズムシ Dendrocoelopsis ezensis Ichikawa et OKugawa.

調查地点におけるプラナリア類の分布は Figures 1,2 に記号で示し，各地点で得られた データは Tables 1,2 に示した。

\section{A. 札幌市（旧市内）}

St. 1 汪北海道大学構内安流れている川（茨户で石特川に注ぐ流れ）で，往時はサヶが 湖行したほぼの清流であつたが，最近では地下水位の低下に伴なつて著しく污濁した。本 地点次幅 $3 \sim 4 \mathrm{~m}$, 水深 $40 \sim 80 \mathrm{~cm}$ 位, 泥底で, ゆるやかな流れである。年間の水温变動

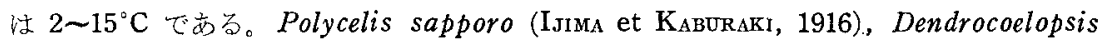
lacteus IChikawa et OKUgawa (1958), Dendrocoelopsis ezensis IChiKaWa et Okvgawa (1958) 3 種の type locality で, 他に D.japonica とPh.iwamai が棲息していた。市 III $(1950)^{* 1}, W_{\text {ATANABE }}$ (1948), 沒辺 - 山岸 (1953), W WTANABE and YaMaGishi (1955), YАмАмото (1957) などの材料恬本地点から採集された。市川 (1950) によると，当時法 Pol. sapporo, Den. lacteus, Den. ezensis の棲息密度が高かつた。そ扎以後川膦の観察 によると，活渭化に伴なつてまず Pol. sapporo 汃見られなくなり，続いてD.japonica，

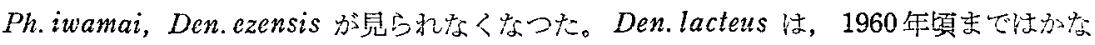
り棲息していたが，1961 年以降注全く見られなくなつた。

St. 2 注新琴似付近の流れで，1956〜1960 年頃は Den.lacteus が豊富に棲急しており， Ph.iwamai, Den.ezensis も僅か棲息していた。ICHIKAWA and IsHu (1961) の材料性, 本地点から採集さ秃た。しかし，最近では，この付近の工場建設と宅地造成が進み，全く プラナリア類は見られなくなつた。

St. 3 注元町の道立開成高等学校の前の小溝 (幅 $50 \mathrm{~cm}$ 位, 深さ $30 \mathrm{~cm}$ 位)で, Ph. iwamai, Den.lacteus, Den.ezensis が棲息しており，特に Den.lacteus の個体数が多い。松田跴 治氏の観察（札遚市郊外に於ける淡水産プラナリアの季節消長 1964. 滕写印刷物）による

*1. 市川 (1950) が記鑯した種のうち, Dugesia gonocephala (DUGES) は Dugesia japonica, Bdellocephala brunnea は Dendrocoelopsis ezensis, Dendrocoelidae 科の 1 種は Dendrocoelopsis lacteus であ る.なお，北海道からイスミオオウズムン Bdellocephala brunnea IJIMA et KABURAKI が探集された との記事 (門馬 1953；OKUaAWA 1953) は誤まりである (DAIM 1963 度び KAWAKATSU 1965 参煦). 


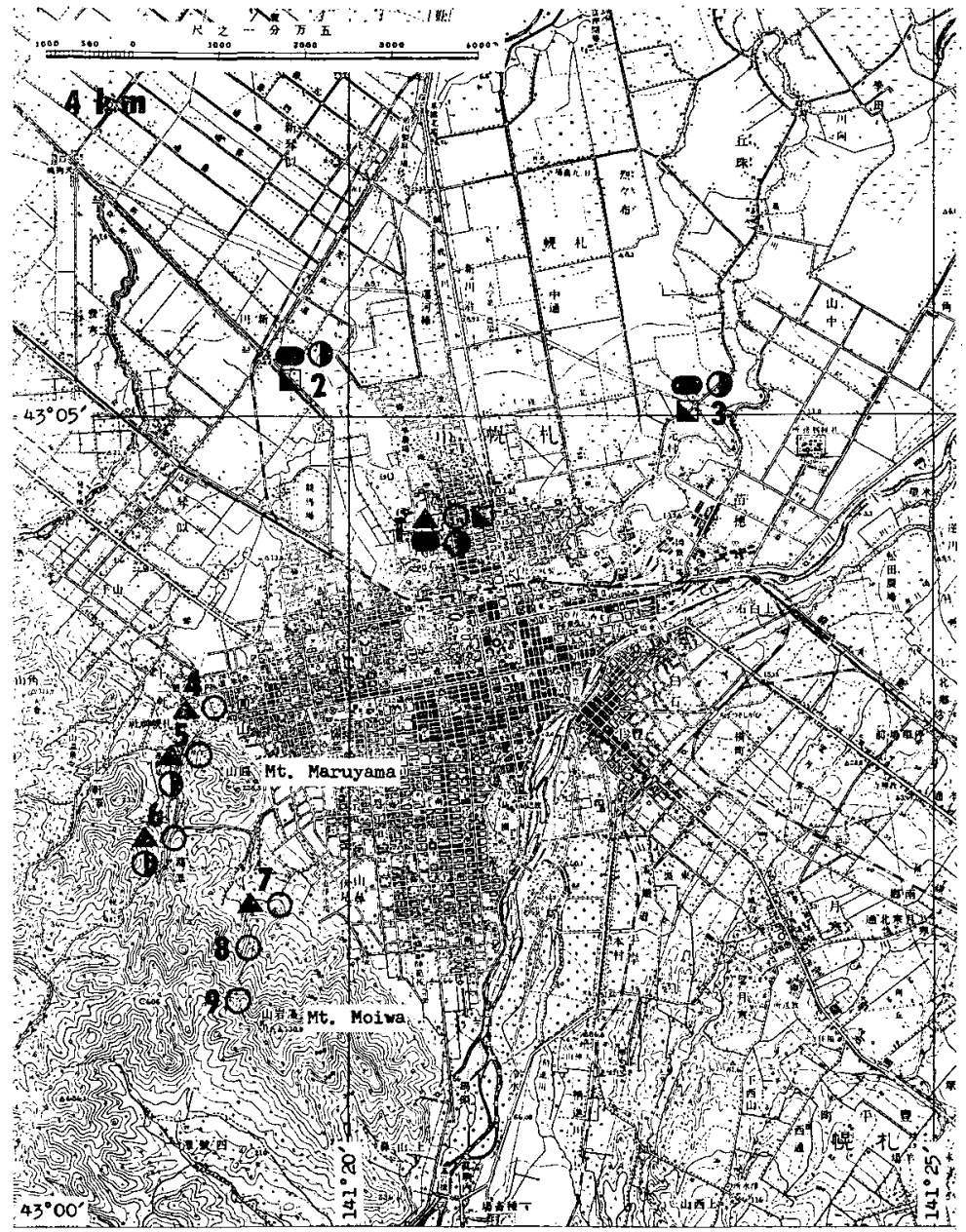

Fig. 1. Map showing the distribution of freshwater planarians in Sapporo City. The data of each station are given in Table 1.

A : Dugesia japonica : Phagocata iwamai $\bigcirc$ : Polycelis sapporo 0 : Dendrocoelopsis lacteus $\square$ : Dendrocoelopsis ezensis 


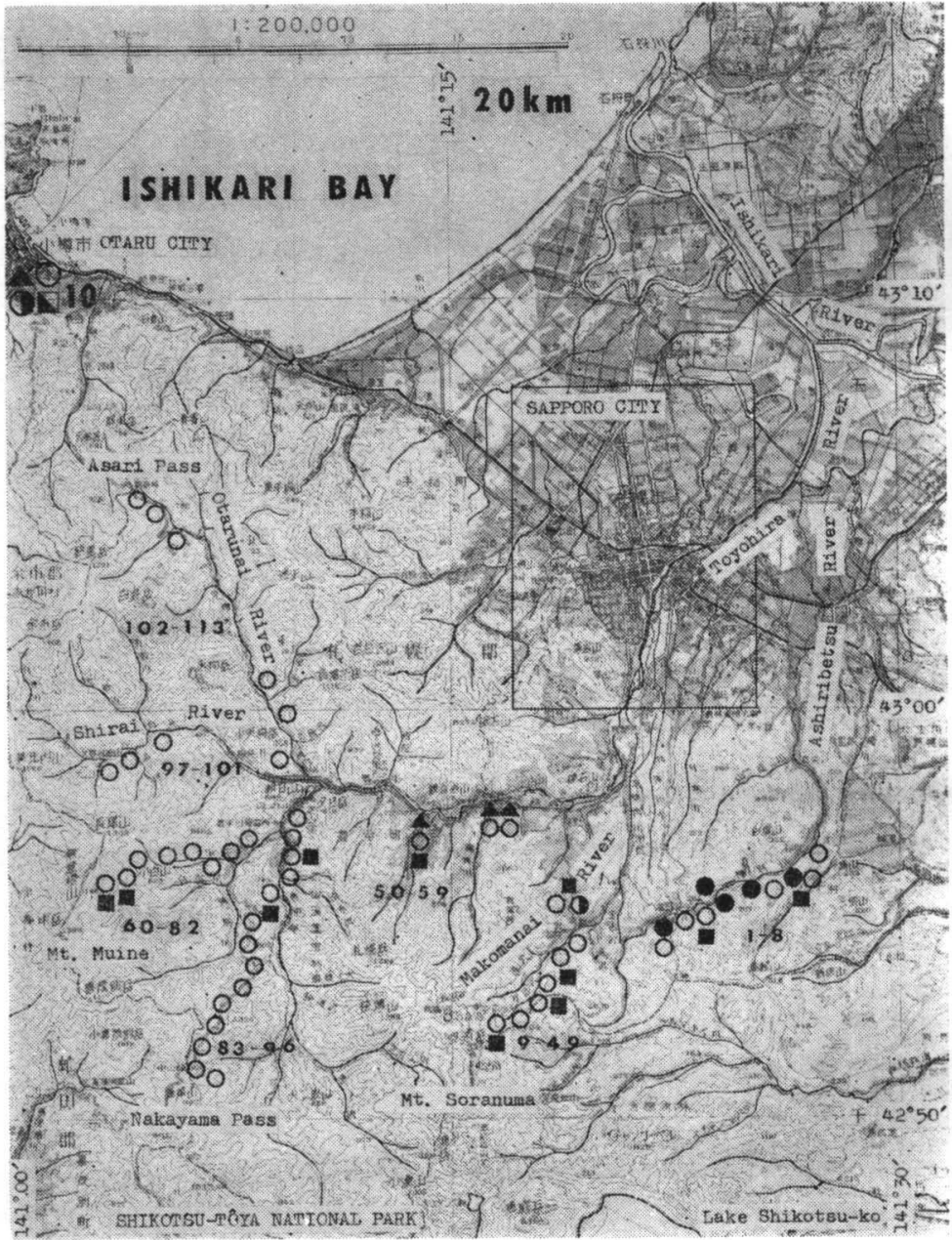

Fig. 2. Map showing the distribution of freshwater planarians in the Toyohira River System. The data of each station are given in Table 2. In general, each symbol on the map indicates several lacalities.
A : Dugesia japonica
: Phagocata vivida
: Polycelis sapporo
: Polycelis auriculata
: Dendrocoelopsis lacteus 
Table 1. The data of 10 stations in Sapporo City and Otaru City

\begin{tabular}{|c|c|c|c|c|c|c|c|c|c|}
\hline $\begin{array}{l}\text { Station and } \\
\text { Locality*1. }\end{array}$ & $\begin{array}{l}\text { Alti- } \\
\text {-tude } \\
\text { (m) }\end{array}$ & $\begin{array}{l}\text { Water } \\
\text { temp. } \\
\left({ }^{\circ} \mathrm{C}\right)\end{array}$ & $\mathrm{pH}$ & $\begin{array}{r}\text { D. japo } \\
\text { nica }\end{array}$ & Ph. & $\begin{array}{l}\text { Specie } \\
\text { Pol. } \\
\text { sapporo }\end{array}$ & $\begin{array}{l}\text { Den. } \\
\text { ezensis }\end{array}$ & $\begin{array}{l}\text { Den: } \\
\text { lacteus }\end{array}$ & . \\
\hline $1^{*}{ }^{\text {Sapporo City, }} \begin{array}{l}\text { Hokkaidô } \\
\text { University }\end{array}$ & 15 & 2. $0 \sim$ & 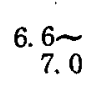 & $y+\operatorname{asex}$ & $+\left(\begin{array}{l}\operatorname{sex} \\
\operatorname{ase} x\end{array}\right.$ & $x+\left(\begin{array}{l}\operatorname{sex} \\
\operatorname{asex}\end{array}\right.$ & $\mathrm{H} H\left(\begin{array}{l}\operatorname{sex} \\
\operatorname{asex}\end{array}\right.$ & $H\left(\begin{array}{l}\text { sex } \\
\text { asex }\end{array}\right.$ & cr. \\
\hline $2 *_{2}$ Kotoni & 10 & $?$ & ? & - & $+\left(\begin{array}{l}\text { sex } \\
\text { asex }\end{array}\right.$ & - & $+\left(\begin{array}{l}\operatorname{sex} \\
\operatorname{asex}\end{array}\right.$ & $H+\left(\begin{array}{l}\operatorname{sex} \\
\text { asex }\end{array}\right.$ & br. \\
\hline 3*3 Motomachi & 8 & 2. $\frac{0 \sim}{19.6}$ & $\begin{array}{l}\text { 6. } 0 \sim \\
6.2\end{array}$ & - & $H\left(\begin{array}{l}\operatorname{sex} \\
\operatorname{asex}\end{array}\right.$ & $\mathrm{x}$ & $H\left(\begin{array}{l}\operatorname{sex} \\
\operatorname{asex}\end{array}\right.$ & Hit $\left(\begin{array}{l}\operatorname{sex} \\
\text { asex }\end{array}\right.$ & br. \\
\hline $\begin{array}{l}\text { Maruyama Park, } \\
4^{*} 4 \mathrm{l}^{\text {Yokoshibetsu }} \\
\text { River }\end{array}$ & 20 & $\begin{array}{r}12.5 \sim \\
19.6\end{array}$ & 7.0 & + asex & - & + ase $x$ & - & - & br. \\
\hline $5^{*} 4 \underbrace{}_{\substack{\text { Maruyama Park, } \\
\text { Yokoshibetsu } \\
\text { River }}}$ & 50 & 15. 2 & 7.0 & + asex & - & + asex & - & + asex & br. \\
\hline $6^{*} 5$ Takinosawa & 100 & $\begin{array}{l}5.0 \sim \\
18.5\end{array}$ & 7.4 & it asex & - & + asex & - & $+\operatorname{sex}$ & br. \\
\hline $7^{*} 6 \mathrm{Mt}$. Moiwa & 40 & 12.5 & 7.2 & + asex & - & + asex & - & 一 & br. \\
\hline $8 * 6 \mathrm{Mt}$. Moiwa & 100 & 12.0 & 7.2 & - & 一 & + asex & 一 & - & br. \\
\hline $9^{*} 6$ Mt. Moiwa $\ldots$ & 200 & 12.0 & 7.2 & - & 一. & + asex & - & - & br. \\
\hline $10^{*} 7 \begin{array}{l}\text { Otaru City, } \\
\text { Nagahashi-chô }\end{array}$ & 10 & $\begin{array}{l}8.0 \sim \\
10.5\end{array}$ & 7. 0 & $H\left(\begin{array}{l}\operatorname{sex} \\
\operatorname{ase} x\end{array}\right.$ & 一 & $+\left(\begin{array}{l}\operatorname{sex} \\
\operatorname{asex}\end{array}\right.$ & $+\operatorname{sex} t$ & $H \operatorname{sex}$ & br. \\
\hline
\end{tabular}

sex : sexually mature state, asex : sexually immature state; cr. : creek, br. : brook or brooklet; + : few, $H$ : medial, H : many.

*1. This station is the type locality of Polycelis sapporo (IJima et $\mathrm{K}_{\mathrm{ABURAKI}}$ ), Dendrocoelopsis lacteus ICHIaWA et OKUGaWA and Dendrocoelopsis ezensis IChikawa et Okugawa. The survey of the station was made by $\mathrm{K}_{\text {AWAKaTSU }}$ during the years 1956 1965. Ecological note about the station was also found in the Japanese article of Prof. InHIKawa (1950).

*2. The survey of the station was also made by Mr. S. IsHIr (cf. ICHIKawa and IsHit 1961).

*3. The survey of the station was also made by Mr. K. MArsuda during the whole year (June, 1963 October, 1964).

*4. The survey of the stations was made by $\mathrm{K}_{\Lambda \mathrm{w}_{A K}} \mathrm{~K}_{\mathrm{T}} \mathrm{su}$ in August and September, 1956. See also Mr. H. Kikuchi's Ecological Survey of Aquatic Animals in the Streem Yokoshibetsu, Sapporo (1956).

*5 The survey of the station was made by $\mathrm{K}_{\text {AWAKaTsu }}$ during the years 1956 $\sim 1964$.

*6. The survey of the stations was made by $\mathrm{K}_{\mathrm{AW}} \mathrm{AKATSO}$ in October, 1962.

*7. The survey of the station was made by KaWAKaTSU in April, 1963 (cf. Teshirogi and Itagaki's 1964 Japanese article). 
Table 2. The data of 113 stations in the Toyohira River System (July and August, 1965)

\begin{tabular}{|c|c|c|c|c|c|c|c|c|c|c|}
\hline & tation and Locality & $\begin{array}{l}\text { Alti- } \\
\text { tude } \\
(\mathrm{m})\end{array}$ & $\begin{array}{l}\text { Water } \\
\text { temp. } \\
\left({ }^{\circ} \mathrm{C}\right)\end{array}$ & $\mathrm{pH} D$ & D. japo- & $\begin{array}{l}\text { Ph. } \\
\text { vivida }\end{array}$ & $\begin{array}{l}\text { pecies } \\
\text { Pol. } \\
\text { sapporo }\end{array}$ & $\begin{array}{l}\text { Pol.auri } \\
\text { culata }\end{array}$ & $\begin{array}{l}\text { i-Den. } \\
\text { lacteus }\end{array}$ & \\
\hline \multirow{8}{*}{ 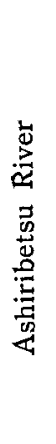 } & 1 Ariake & 100 & 12.5 & 7.0 & 一 & - & + asex & - & 一 & br. \\
\hline & 2 & 160 & 7.8 & 7.4 & - & + asex & $t \operatorname{asex} t$ & H asex & - & br. \\
\hline & $\begin{array}{l}3 \text { Mitaki-no-sawa } \\
\text { V. }\end{array}$ & 170 & 11.3 & 7.2 & - & - & 一 & - & 一 & br. \\
\hline & 4 & 180 & 7.9 & 7.4 & - & + asex & + asex & 一 & - & br. \\
\hline & 5 Shimamatsu & 190 & 8.5 & 7.4 & - & $H$ ase $x$ & $+\operatorname{sex}$ & 一 & 一 & br. \\
\hline & 6 Takino & 230 & 10.8 & 7.2 & 一 & + asex & $+\operatorname{sex} t$ & tt asex & 一 & br. \\
\hline & $\begin{array}{l}7 \text { Takino, } \\
\text { Ashiribetsu R. }\end{array}$ & 230 & 15.8 & 7.4 & 一 & 一 & $+\left(\begin{array}{l}\operatorname{sex} \\
\text { asex }\end{array}\right.$ & - & - & riv. \\
\hline & $\begin{array}{c}8 \text { Takino, } \\
\text { Ashiribetsu } \\
\text { Waterfall }\end{array}$ & 230 & 9.2 & 7.4 & - & H asex & + asex & - & - & br. \\
\hline \multirow{11}{*}{ 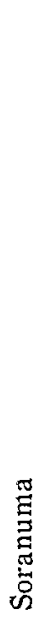 } & 9 Tokiwa & 150 & 18. 0 & 7.2 & - & - & - & - & 一 & br. \\
\hline & 10 Tokiwa P. School & 160 & 17.1 & 7.2 & - & 一 & - & 一 & - & br. \\
\hline & 11 Tokiwa P. School & 160 & 10. 0 & 7.4 & 一 & - & $+\left(\begin{array}{l}\operatorname{sex} \\
\operatorname{asex}\end{array}\right.$ & $H$ asex & $+\operatorname{sex}$ & spr. \\
\hline & 12 Futamata & 180 & 17.8 & 7.2 & - & 一 & $+\left(\begin{array}{l}\operatorname{sex} \\
\operatorname{asex}\end{array}\right.$ & - & 一 & br. \\
\hline & 13 & 185 & 17.9 & 7.2 & - & - & - & 一 & - & br. \\
\hline & 14 Yunosawa Valley & 200 & 18. 0 & 7.2 & - & - & - & - & 一 & br. \\
\hline & $\begin{array}{l}15 \text { Makomanai } \\
\text { River }\end{array}$ & 260 & 16.4 & 7.4 & 一 & - & - & - & - & riv. \\
\hline & $\begin{array}{l}16 \text { Entrance of the } \\
\text { Mt. Soranuma's } \\
\text { Path }\end{array}$ & s 280 & 13.6 & 7.2 & 一 & - & + asex & + asex & - & br. \\
\hline & 17 & 285 & 12.3 & $7.2^{+}$ & asex & 一 & $+\left(\begin{array}{l}\operatorname{sex} \\
\operatorname{asex}\end{array}\right.$ & 一 & 一 & br. \\
\hline & $\begin{array}{c}18 \text { Bankei-zawa } \\
\text { Valley }\end{array}$ & 290 & 19.0 & 7.0 & - & - & - & 一 & 一 & riv. \\
\hline & 19 & 300 & 16.0 & 7.0 & - & - & + asex & - & - & br. \\
\hline \multirow{6}{*}{ 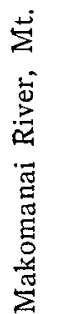 } & 20 & 320 & 14.2 & 7.2 & 一 & - & $t$ asex $t$ & $H$ asex & - & br. \\
\hline & 21 & 325 & 13. 2 & 7.2 & - & - & $H$ ase $t$ & H asex & 一 & br. \\
\hline & 22 & 330 & 16.2 & 7.2 & - & - & $+\operatorname{sex}$ & - & 一 & spr. \\
\hline & 23 & 350 & 11.9 & 7.6 & - & - & $H\left(\begin{array}{l}\operatorname{sex} \\
\operatorname{asex}\end{array}\right.$ & $H$ asex & - & br. \\
\hline & 24 & 360 & 8. 4 & 7.6 & - & - & $H\left(\begin{array}{l}\operatorname{sex} \\
\text { asex }\end{array}\right.$ & $H$ asex & - & br. \\
\hline & 25 & 370 & 16.0 & 7.0 & 一 & 一 & + asex & - & 一 & br. \\
\hline
\end{tabular}


1965]

\begin{tabular}{|c|c|c|c|c|c|c|c|c|c|c|}
\hline Station and Locality & $\begin{array}{l}\text { Alti- } \\
\text { tude } \\
\text { (m) }\end{array}$ & $\begin{array}{l}\text { Water } \\
\text { temp. } \\
\left({ }^{\circ} \mathrm{C}\right)\end{array}$ & $\mathrm{pH} D$ & $\begin{array}{l}\text { Dapo- } \\
\text { nica }\end{array}$ & $\begin{array}{l}\text { Ph } \\
\text { vivida }\end{array}$ & $\begin{array}{r}\mathrm{Spe} \\
P o l \\
s a p\end{array}$ & $\begin{array}{l}\text { ci i s } \\
l \text { bporo }\end{array}$ & $\begin{array}{l}\text { Pol.auri } \\
\text { culata }\end{array}$ & $\begin{array}{l}i-\text { Den. } \\
\text { lacteus }\end{array}$ & \\
\hline $\begin{array}{c}26 \text { Bankei-zawa } \\
\text { Valley }\end{array}$ & 380 & 13.8 & 7.0 & 一 & - & & - & - & - & riv. \\
\hline 27 & 390 & 19.7 & 7.4 & - & - & + & asex & - & 一 & br. \\
\hline 28 & 400 & 15.6 & 7.6 & - & - & + & asex & + ase $x$ & 一 & br. \\
\hline 29 & 410 & 15.6 & 7.6 & 一 & - & + & asex & - & 一 & br. \\
\hline 30 & 420 & 15.8 & 7.6 & 一 & 一 & + & $\left(\begin{array}{l}\operatorname{sex} \\
\operatorname{asex}\end{array}\right.$ & 一 & - & br. \\
\hline 31 & 430 & 15.7 & 7. 6 & 一 & - & H & asex & + asex & - & dr. \\
\hline 32 & 450 & 12.0 & 7.6 & 一 & 一 & + & asex & + asex & - & dr. \\
\hline 33 & 460 & 19.0 & 7.6 & - & 一 & + & asex & - & - & $\mathrm{dr}$ \\
\hline $\begin{array}{c}34 \text { Bankei-zawa } \\
\text { Valley }\end{array}$ & 470 & 13.2 & 7.2 & - & - & & - & - & - & cr. \\
\hline 35 & 500 & 8.8 & 7.6 & 一 & - & + & asex & + asex & 一 & br. \\
\hline $\begin{array}{c}36 \text { Bankei-zawa } \\
\text { Valley }\end{array}$ & 520 & 14.2 & 7.2 & - & - & & 一 & + asex & - & cr. \\
\hline 37 & 530 & 14.0 & 7.6 & - & - & & - & - & - & br. \\
\hline 38 & 540 & 14.0 & 7.4 & - & - & & - & - & - & br. \\
\hline 39 & 550 & 12.8 & 7.6 & - & - & & - & + asex & - & br. \\
\hline 40 & 600 & 14.8 & 7. 6 & - & - & + & asex & 一 & 一 & br. \\
\hline 41 & 700 & 7.3 & 7.4 & 一 & - & + & $\left(\begin{array}{l}\operatorname{sex} \\
\operatorname{asex}\end{array}\right.$ & $+\operatorname{asex}$ & - & br. \\
\hline 42 & 730 & 12.0 & 7.4 & 一 & - & & - & + asex & - & br. \\
\hline 43 & 750 & 9.9 & 7.6 & - & - & + & asex & + asex & 一 & br. \\
\hline $\begin{array}{c}\text { Bankei-zawa } \\
\text { Valley }\end{array}$ & 800 & 10.9 & 7.6 & - & - & & 一 & + asex & 一 & cr. \\
\hline $\begin{array}{c}45 \text { Bankei-zawa } \\
\text { Valley }\end{array}$ & 820 & 10.7 & 7.6 & - & 一 & & - & $H$ asex & - & cr. \\
\hline 46 & 850 & 11.3 & 7.2 & - & 一 & + & asex & - & - & br. \\
\hline 47 & 900 & 8.4 & 7.0 & - & - & & ( $\begin{array}{l}\text { sex } \\
\text { asex }\end{array}$ & 一 & - & spr. \\
\hline 48 Bankei-numa & 920 & 16.4 & 7.4 & - & - & & - & - & - & pond \\
\hline 49 Masumi-numa & 1040 & $\begin{array}{r}\text { 18. } 3 \sim \widetilde{ } \\
19.4\end{array}$ & 6.6 & - & - & & - & 一 & - & pond \\
\hline 50 Jûgoshima Park & 200 & 13.9 & $7.0 H$ & + asex & - & + & $\operatorname{sex}$ & - & - & br. \\
\hline 51 Takinosawa & 190 & 19.8 & $7.6+$ & asex & - & & - & - & - & br. \\
\hline స 52 Takinosawa & 220 & 17.4 & 7.4 & - & 一 & + & asex & - & - & br. \\
\hline 53 Takinosawa & 300 & $\begin{aligned} 11.4 \widetilde{4} \\
11.5\end{aligned}$ & 7.2 & - & - & $H$ & $\left(\begin{array}{l}\text { sex } \\
\text { asex }\end{array}\right.$ & tt asex & - & cr. \\
\hline
\end{tabular}




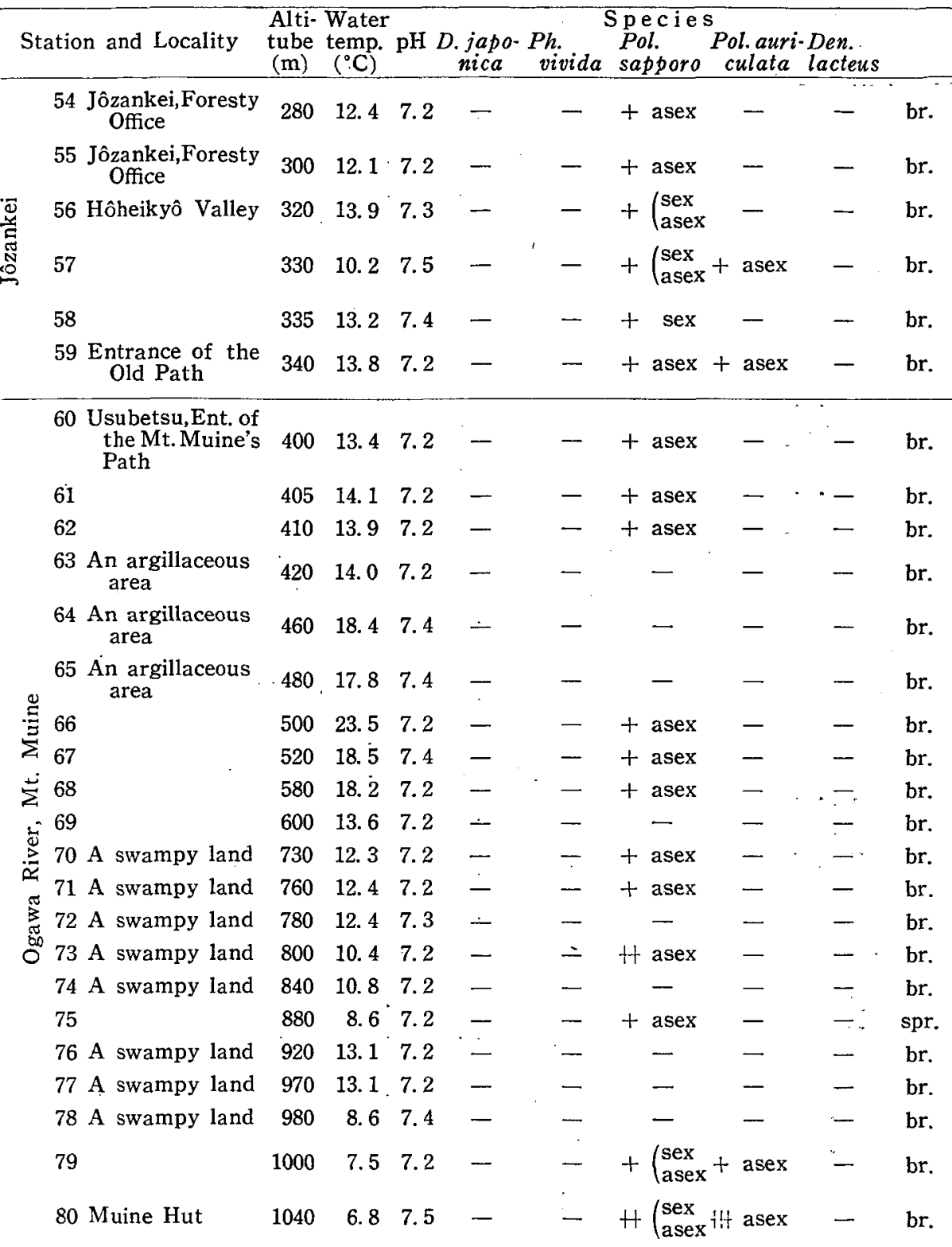




\begin{tabular}{|c|c|c|c|c|c|c|c|c|c|c|c|}
\hline \multicolumn{2}{|r|}{ Station and Locality. } & \multicolumn{4}{|c|}{$\begin{array}{l}\text { Alti- Water } \\
\text { tude temp. pH } D . \text { japo- } \\
(\mathrm{m}) \quad\left({ }^{\circ} \mathrm{C}\right)\end{array}$} & \multicolumn{5}{|c|}{$\begin{array}{l}\text { Species } \\
\text { Pol. Pol.auri-Den. } \\
a \text { sapporo culata lacteus }\end{array}$} & \multirow{3}{*}{$\begin{array}{l}\text { br. } \\
\text { br. }\end{array}$} \\
\hline & 81 Snowy Valley & 1060 & 6.8 & 7.5 & 一 & 一 & $H$ & $\left(\begin{array}{l}\operatorname{sex} \\
\text { asex }\end{array}\right.$ & $x$ Ht asex & - & \\
\hline & 82 Snowy Valley & 1090 & 4.5 & 7.5 & - & - & $:+$ & $\operatorname{sex}$ & H asex & - & \\
\hline \multirow{14}{*}{ 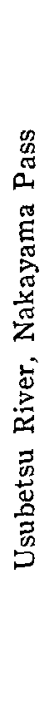 } & $\begin{array}{l}83 \text { Bus road to the } \\
\text { Nakayama Pass }\end{array}$ & 410 & 17.4 & 7.0 & 一 & - & + & asex & 一 & - & br. \\
\hline & 84 & 560 & 14. 4 & 7.0 & - & - & & - & - & - & br. \\
\hline & 85 & 600 & 17.3 & 7.0 & - & - & & $\left\{\begin{array}{l}\text { sex } \\
\text { asex }\end{array}\right.$ & - & - & r. \\
\hline & 86 & 620 & 16.0 & 7.2 & - & - & & $\left(\begin{array}{l}\operatorname{sex} \\
\operatorname{asex}\end{array}\right.$ & - & - & br. \\
\hline & 87 & 760 & 13.5 & 7. 4 & - & 一 & + & asex & - & - & r. \\
\hline & 88 A swamph land & 810 & 16. 0 & 6.8 & 一 & - & & $\longrightarrow$ & - & 一 & r. \\
\hline & 89 & 810 & 12.1 & 7.0 & - & 一 & + & asex & 一 & - & 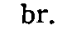 \\
\hline & 90 A swampy land & 830 & 11.9 & 7.2 & 一 & 一 & & - & 一 & - & r. \\
\hline & 91. A swampy land & 830 & 10. 8 & 7.2 & - & - & + & $\operatorname{sex}$ & - & - & r. \\
\hline & 92 A swampy land & 820 & 12.4 & 7.0 & 一 & 一 & & - & 一 & - & r. \\
\hline & 93 A swampy land & 810 & 10. 1 & 7.0 & - & 一 & & - & 一 & - & r. \\
\hline & 94 & 790 & 9. 6 & 7.0 & - & - & & asex & - & - & br. \\
\hline & 95 Nakayama Pass & 835 & 11.9 & 7.2 & - & - & & $\left(\begin{array}{l}\operatorname{sex} \\
\operatorname{asex}\end{array}\right.$ & 一 & - & spr. \\
\hline & $\begin{array}{l}96 \text { Nakayama Pass, } \\
\text { source }\end{array}$ & 860 & 12.1 & 7.0 & - & 一 & & asex & - & - & br. \\
\hline \multirow{5}{*}{ 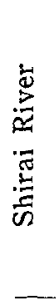 } & 97 Onko-no-sawaV. & 350 & 16. 2 & 7.2 & - & - & & - & 一 & - & br. \\
\hline & 98 & 450 & 9.8 & 7.4 & - & 一 & & ( $\begin{array}{l}\text { sex } \\
\text { asex }\end{array}$ & $\tau$ & - & br. \\
\hline & $\begin{array}{l}99 \text { Koyanagi-zawa } \\
\text { V. }\end{array}$ & 455 & 16. 4 & 7.8 & 一 & 一 & + & asex & - & - & br. \\
\hline & 100 Motoyama & 460 & 16. 4 & 7.8 & 一 & - & + & asex & - & - & br. \\
\hline & $\begin{array}{l}101 \text { Toyoha Silver } \\
\text { Mine, Yunosawa } \\
\text { V. }\end{array}$ & 480 & 16.2 & 7.8 & - & - & & - & - & - & cr. \\
\hline \multirow{7}{*}{ 苞 } & $\begin{array}{l}102 \text { Motor road to the } \\
\text { Assri Pass }\end{array}$ & 380 & 13.2 & 7.4 & - & - & + & sex & - & - & br. \\
\hline & 103 Inaho Mine & 420 & 8. 7 & 7.2 & - & - & & asex & - & - & spr. \\
\hline & 104 & 430 & 12.9 & 7.2 & - & - & & - & - & - & br. \\
\hline & 105 & 440 & 13. 9 & 7.2 & - & - & & - & - & - & br. \\
\hline & 106. Shirakaba Hütte & 520 & 16. 0 & 7.2 & - & - & & - & - & - & br. \\
\hline & 107 Fumoto Bridge & 640 & 16. 8 & 7.2 & - & - & & - & - & - & br. \\
\hline & 108 & 670 & 15.0 & 7.2 & - & - & & asex & - & - & br. \\
\hline
\end{tabular}




\begin{tabular}{|c|c|c|c|c|c|c|c|c|c|}
\hline Station and Locality & $\begin{array}{l}\text { Alti- } \\
\text { tude } \\
\text { (m) }\end{array}$ & $\begin{array}{l}\text { Water } \\
\text { temp. } \\
\left({ }^{\circ} \mathrm{C}\right)\end{array}$ & $\mathrm{pH} L$ & $\begin{array}{l}\text { D. japo- } \\
\text { nica }\end{array}$ & $\begin{array}{l}\text { Ph. } \\
\text { vivida }\end{array}$ & $\begin{array}{l}\text { Species } \\
\text { Pol. } \\
\text { sapporo }\end{array}$ & $\begin{array}{l}\text { Pol.auri- } \\
\text { culata }\end{array}$ & $\begin{array}{l}\text { Den. } \\
\text { lacteus }\end{array}$ & \\
\hline 109 & 690 & 16.3 & 7. 2 & - & 一 & - & - & - & br. \\
\hline 110 & 700 & 15.0 & 7.2 & - & - & - & - & - & br. \\
\hline $\begin{array}{l}111 \text { Asari Pass, } \\
\text { swampy land }\end{array}$ & 700 & 15.0 & 7.2 & - & - & $+\left(\begin{array}{l}\operatorname{sex} \\
\text { asex }\end{array}\right.$ & - & 一 & br. \\
\hline $\begin{array}{l}112 \text { Asari Pass, } \\
\text { swampy land }\end{array}$ & 700 & 16.8 & 7.4 & - & - & $+\operatorname{sex}$ & - & - & br. \\
\hline $\begin{array}{l}113 \text { Tôge Bridge, } \\
\text { Otarunai Riv., } \\
\text { source }\end{array}$ & 700 & 13.8 & 7.2 & 一 & 一 & $+\operatorname{sex}$ & 一 & - & cr. \\
\hline
\end{tabular}

sex : sexually mature state, asex: sexually immature state; riv. : river, cr. :creek, br. : brook or brooklet, spr. : spring; + : few, H : medial, H : many.

* 1 . The first and the second surveys of the stations, Nos. 50 54, were made by $K_{A W A K a t s u}$ in September 13,1956 and in September 5, 1957.

と, 年間の水温変動は $2.0 \sim 19.6^{\circ} \mathrm{C}$ で, Ph. iwamai は晚秋〜早春の時期に個体数が増加 乙, Den. lacteus は夏季に個体数が增加するが, Den.ezensis は通年個体数変動が認めら れない(山田 1965a, b参照)。

St. 4, St. 5 注山山公園を流れているヨコシベツ川 (琴似川の小支流)で, 川幅 $3 \mathrm{~m}$ 位, 深さ $20 \mathrm{~cm}$ 位の涘流である。D.japonica と Pol. sapporo が少数棲息しているが, KıкUCHI (1956) によると，この水系から Dendrocoelopsis sp. (Dendrocoelopsis lacteus) が採集されている。

St. 6 は滝ノ沢のアフター・ケアー前の小瑇で, 多数の D.japonica, 少数の Pol.

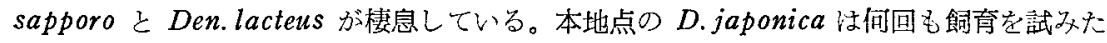
が, 生殖個体は得られなかつた。

St. 7〜St. 9 注藻岩山の渓流で，Pol.sapporo が少数得られた。札㨪市内では，なおい くつかの地点でプラナリアが採集されているが，低地部では Den.lacteus と Den.ezensis が，山地部では Pol.sapporo が普通に見出される。

St. 10 は小楚市長橋町の長橋小学校校庭の小溝で, D. japonica, Pol. sapporo, Den. lacteus, Den. ezensis が棲息している。本地点の D. japonica 注，手代木・板桓 (1965) の核型分析の研究に使用された $(2 \mathrm{n}=16, \mathrm{n}=8)$.

B. 豊平川水赤

a. 漳品川 別川

豊平川下流部に流入する水系で，源流部は鳥松山 $(512 \mathrm{~m})$ の北斜面である。St. 1 注この 水系の中流部の有明部落, St.6〜St.81厚別の滝付近である。Pol. sapporo と Ph. vivida が多く, 涌水流や水温の低い地点からはPol. auriculata が出現した。St. 8 は㳶の直下の 
涌水流で，特にPh.vivida の棲息密度が高く，容易に数百個体学採集できるほどである。 虫は, 黒色で小さく, 生殖個体は得られなかつた。なお，Ph.vividaは，札幌市近郊では 厚別川水系以外では得られなかつた。

\section{b. 真駒内川 空沼岳}

真駒内川は真駒内付近で豊平川に流入する一支流で，上流部は湯ノ沢と万計沢とに分忮 している。空召岳 $(1,251 \mathrm{~m})$ 汪空沼山群 (札幌㐍, 狭薄山, 空沼岳) の主案で, 山頂部 付近には大小の沼（万計沼，真篻沼，長沼，空沼など）が点在している。

St. 9, St. 10 嫦盤小中学校付近の流机㐫る。St. 11 は常盤の真駒内川左岸の小湧家 で, Pol. sapporo と Den.lacteus が出現した。

St. 12, St. 13 は空沼岳登山口の二股の小流, St. 14 St. 48 は登山道（旧道；万訳沢） 沿いの小流, 涌泉及び本流である。これらの地点の大部分に Pol. sapporo が棲息してお り, やや水温の低い地点では Pol. auriculata の混棲が認められた。D.japonica は標高 $285 \mathrm{~m}$ の地点 (St. 17) 加らだけ得られた。万計沢本流中では，多くの場合プラナリアが 得られなかつた。

St. 48 は万計沼（標高 $920 \mathrm{~m}$; 空沼小屋の前）で, 万訳沢の源流部である。周囲 $1 \mathrm{~km}$ 位の浅い沼で文るが，沼岸ではプラナりアを採集できなかつた。 St. 49 は真筑沼（標高 $1,040 \mathrm{~m})$ で, 周囲 $5 \mathrm{~km}$ 位の大きい沼である。沼岸の数地点を調酉したが，プラナリア は得られなかつた。

c. 十五鼠公園一滝, 沢

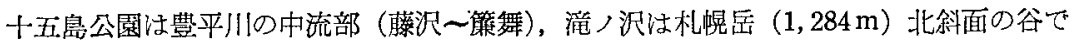
方る。

4 地点 (St. 50 - St. 53) 老調查し, D. japonica, Pol. sapporo, Pol. auriculata 家得 た。St.53の Pol. auriculata は，1956年以降数回採集して飼育したが，生殖個体は得ら えていない。

d. 定山湑一䨐立峡

St. 54 注定山溪営林署横の小流, St. 55 注浄水場横の流れで, Pol. sapporo が出現し た。St. 56, St. 57 は豊平峡の入口, St. 58 は札猊岳西北斜面の落水流, St. 59 注泊道入 口付近である。これらの地点では Pol. sapporo が挡通で, Pol. auriculata の梖息も認め られた。

e. 小川〜無意根山

無意根山 $(1,461 \mathrm{~m})$ は定山深の西南方儿位置す万無意根山群（美比内山，長尾山，無

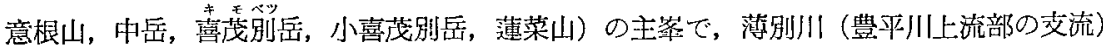
の支流沿いに登山道が通じている。無意根山の中腹部には湿地と粘上地带が多い。

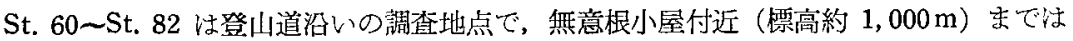
Pol. sapporo が楼息しており，九れより栖高の高い地域（St. 79〜St. 82 ; 雪溪からの流 


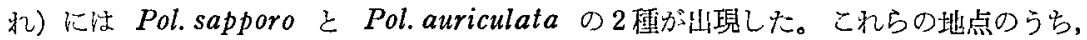
St. 63〜St. 65 は赤粘土地带, St. 76〜St. 78 は泥炭地帯で，プラナリア類は得られなふ つた。

f. 中r 山岒

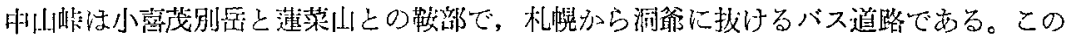

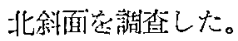

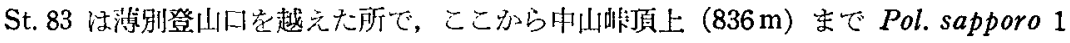
程類だけが出現した。St. 95 湴上部の涌宗で，特に棲息個体数が多かつた。この地域に も泥炭鼬地があり，多くの場合プラナリア類注採集されなからた。

\section{g. 它井川}

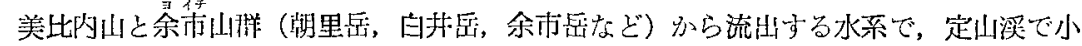
標内川と合流して豊非川に注いでいる。

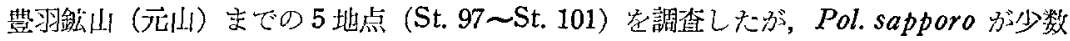
得られたに過ぎない。この付近の本流は銀鉣山の廃水が流入しておりプラナリア類は得 ら机な吅つた。

h. 朝 里 婥

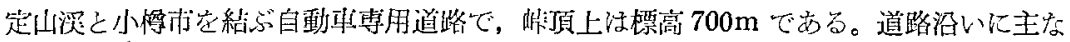
地点定㯝んで調查した。

この地域にも Pol. sapporo 1 種だけ多活現した。St.110〜St. 112 は腙頂上付近の湿地， St. 113 注岞橋の下で，小樽内川の源流部である。

\section{その他の地域（渡鼠地方）}

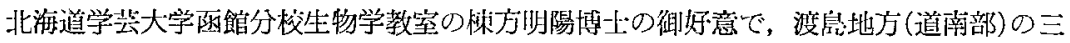

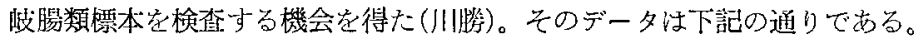

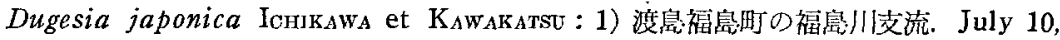
1965. 水温 $14^{\circ} \mathrm{C}$; June $26,1965.14^{\circ} \mathrm{C}$

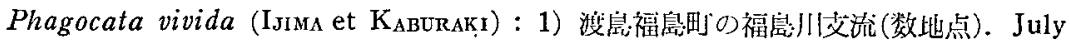
$10,1965.14^{\circ} \mathrm{C}$; June $26,1965.14^{\circ} \mathrm{C}$; July $21,1965.12^{\circ} \mathrm{C}$; Aug. $10,1965.18^{\circ} \mathrm{C}$. 2) 牦

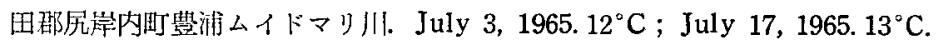

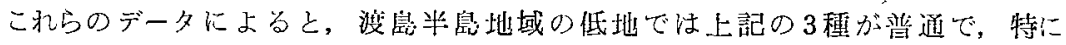
D. japonica と Ph. vivida の梅息倜体数が多い。な掞，市川教授の調查（市川1954）によ

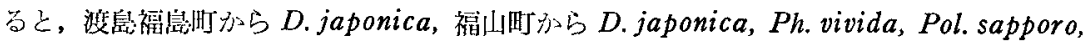
汇差町方与 Ph. vivida, Pol. sapporo 老龍録されている。

$$
\text { ま と め }
$$

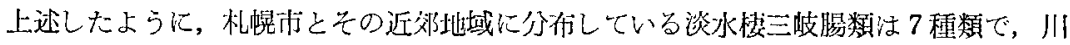


Table 3. The maximum and minimum water temperature and $\mathrm{pH}$ concentration of the habitats of four species of planarians in Sapporo City and its adjacent district. The data of the stations where planarians were not found are excluded from this table.

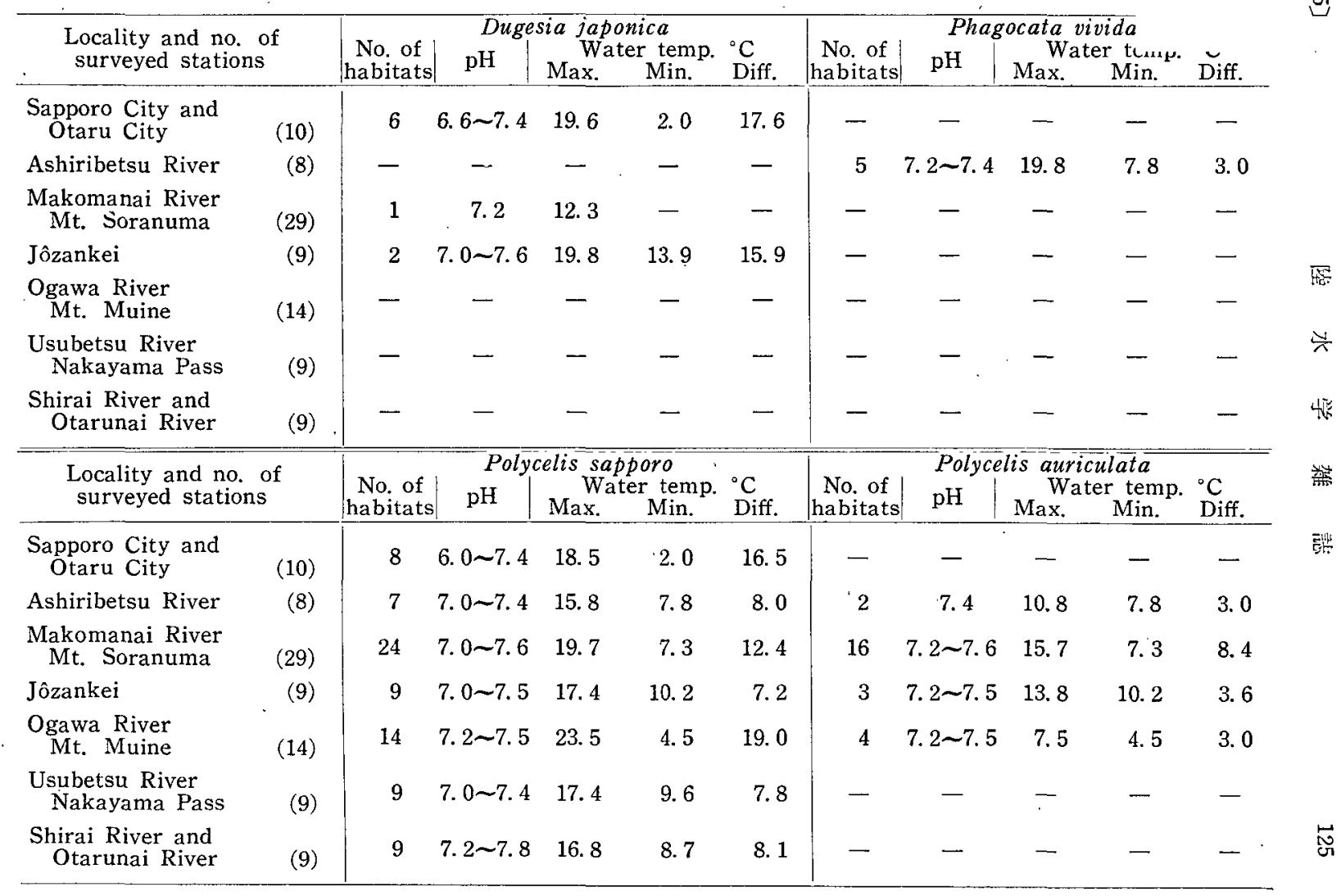




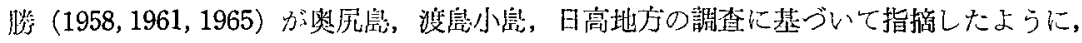

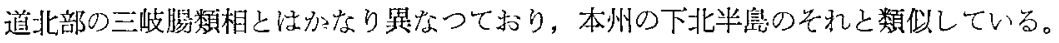

上記の7程類の5ち Ph.iwamai, Den.lecteus, Den.ezensis は主として石特低地带に だけ分布している。D.japonica は平地にだけ分布しているが，その楼息地は少ない。 Ph. vivida は，道南部で潽道程であるにも拘わらず，札幌方近郊で注厚则川水系にだけ 分行している。この理由は，現在ではなお昒らかでないが，本種は本州から北上してきて

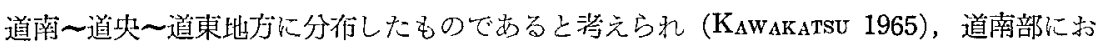

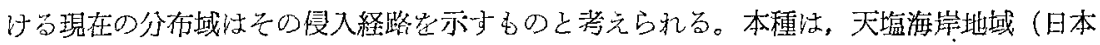

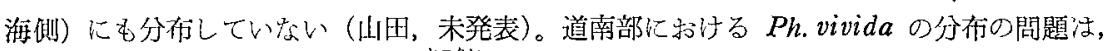

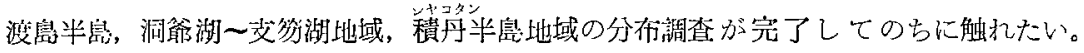
Pol. sapporo は北海道の全地域に分布している㫮通程で，札昆市近郊にも広く分布してい ることが明ら尔になつた。Pol. aurnculataは, 当地域の山地部にはかなり広く分布してい る。

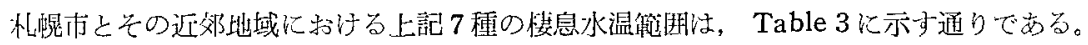
また, D. japonica(J), Ph. vivida (V), Pol.sapporo (S), Pol.auriculata (A) 04 種

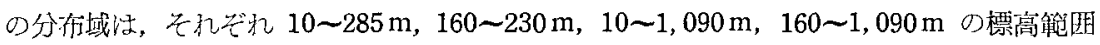

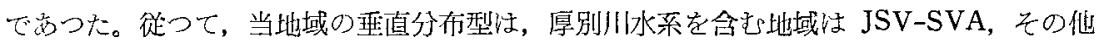

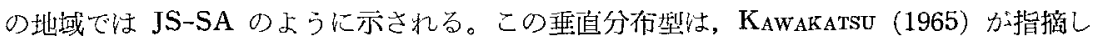
た道南一道决部の模式仙な堽直分布型 JSV-SVA-VA-A の一部を无している。

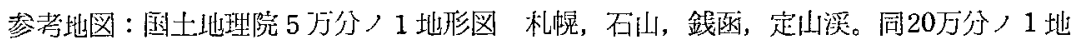
梦图 札管.

可用文献

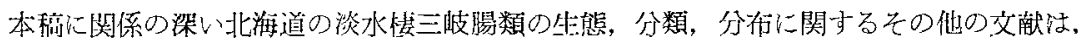
KAWAKaTSU (1965) の References 参照されたい。

DAнм, A. G.: The karyotypes of some freshwater Triclads from Europe and Japan (Turbellaria Tricladida Paludicola). Arkiv Zoologi, 16, 41 67, 1963.

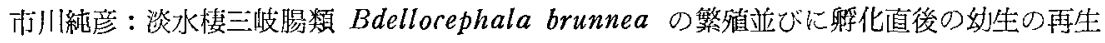

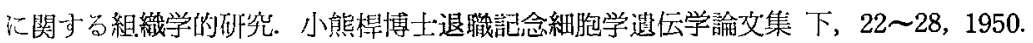

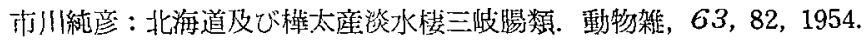

ICnIKAWA, A. and ISHI, S.: Morphological and histochemical studies on regeneration in a freshwater planarian, Dendrocoelopsis lacteus. Jour. Fac. Sci. Hokkaidô Univ., VI, Zool., 74 (4), 595 606+Pl. XVI, 1961.

ICHIKaWA, A. and KawaKatsu, M.: Phagocata iwamai, a new freshwater planarian, from Hokkaidô. Annot. Zool. Japon., 35, 38 46, 1962.

IOHIKaWA, A. and Kawakatsu, M.: A new freshwater planarian, Dugesia japonica, commonly but erroneously known as Dugesia gonocephala (Dugìs). Annot. Zool. Japon., 37, 185 194, 1964. 
IChikaWA, A. and Okugawa, K. I. : Studies on the probursalian (fresh-water Triclads) of Hokkaidô. I. On two new species of the genus Dendrocoelopsis KENK, D. lacteus and D.ezensis. Bull. Kyoto Gakugei Univ., B, 12, 9 18+Pls. 1 5, 1958.

IJIMA, I. and KABURAKI, T. : Preliminary descriptions of some Japanese Triclads. Annot. Zool. Japon., 9, 153 171, 1916.

川勝正治：淡水産プラナリアの垂直分布に関する資料. I. 大山地方. 京都学芸大学学報, B, 7, 45〜51, 1955.

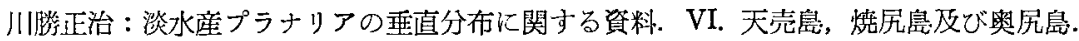

京都学芸大学学報, B, 13, 36〜 51, 1958.

川勝正治 : 下北半岛の淡水産プラナリアの生態調查報告. 京都学芸大学学報, $\mathrm{B}, 17,70 \sim$ 85, 1961.

川勝正治：日高地方の淡水産プラナリアの生態調查報告. 日生態会誌, $15,173 \sim 183,1965$. 川勝正治：淡水棲三岐腸類の生態調査法. 日生態会誌，16，印刷中，1966.

$\mathrm{K}_{\text {AWAKATSU, }}$ M. : On the ecology and distribution of freshwater planarians in the Japanese Islands, with special reference to their vertical distribution. Hydrobiologia, 26, 349 408. 1965.

KIKUCH, H. : Ecological survey of aquatic animals in the stream Yokoshibetsu,

Sapporo. Jour. Eac. Sci. Hokkaidô Univ., VI, Zool., 12 (3), 401 411, 1956. 門馬栄治：イズミオオりズムシの染色体．染色体，16,573〜574，1953.

OkUgawa, K. I. : A monograph of Turbellaria (Acoela, Rhabdocoela, Alloeocoela and Tricladida) of Japan and its adjacent regions. Bull. Kyoto Gakugei Univ., B, 3, 20 43, 1953.

手代木渉・板桓源太郎：Dugesia gonocephala とよばれてきた本邦淡水産プラナリア Dugesia species の核型. 動物雑, 74, 38 45, 1965.

Watanabe, Y.: Physiological studies on a fresh water Triclad, Polycelis sapporo.

I. Character and rate of reconstitution of transverse pieces in relation to level of body. Jour. Exper. Zoöl., 109, 291 329, 1948.

渡辺 勇・山岸静夫 : 三岥晹虫ポリケリスの示差感受性と示差酸化還元. 茨城大学文理学 部紀要 (自然科学) $, 3,56 \sim 72,1953$.

WATANABE, Y. and Y YMAGISHI, S.: Differential susceptibility and redox indicator patterns in Polycelis sapporo. Physiol. Zoöl., 28, 1 18, 1955.

山田達也：名寄市の湧水流におけるプラナリア類の生態に関する硎究. I-II. 3 種の季節的 移動； 3 種の生活史. 動難, 74, 156 164；226 237, 1965.

Yamamoto, T.S.: Histochemistry of the fresh-water planarian, Dendrocoelopsis sp. Annot. Zool. Japon., 30, 150 155, 1957. 
In this paper, the vertical distribution of freshwater planarians in Sapporo City and its adjacent district in Central Hokkaidô is reported. Sapporo City is situated at the northern part of the Ishikari lowland area. Its adjacent district is the lower mountainous land (the highest peak, Mt. Yoichi-dake, is 1488 metres above sea level). The main river system in the area surveyed is the Toyohira River (the large tributary of the Ishikari River which enters into the Ishikari Bay, the Sea of. Japan). Surveys of the stations in Sapporo City were made during the years 1956 1965. Surveys of the majority of the other stations were made in July and August, 1965.

In the area surveyed, seven species of freshwater planarians, Dugesia japonica IChIKaWa et $\mathrm{K}_{\mathrm{AWAKaTSU}}$ Phagocata vivida (InMA et $\mathrm{K}_{\text {ABURAKI), Phagocata iwamai }}$ IchikaWa et $\mathrm{K}_{\mathrm{AWAKaTSO}}$, Polycelis sapporo (IJIMA et $\mathrm{K}_{\mathrm{ABURAKI}}$ ), Polycelis auriculata IJIMA et KaBURAKI, Dendrocoelopsis lacteus IoHIKaWA et OKUGAWA and Dendrocoelopsis ezensis Ionikawa et Okdgawa, were found. Ph. iwamai, Den.lacteus and Den.ezensis were found only in the biotopes in the Ishikari lowland area. D.japonica was found in the biotopes below the altitude of about 285 metres. Ph.vivida, one of the common planarian species in South and Central Hokkaido, was found only in the brooks, brooklets and springs in the Ashiribetsu River (one of the tributary of the Toyohira River). Pol. sapporo was most common in the biotopes both in the plain and the mountainous district. Pol. auriculata was rather common in the biotopes within the altitude range from about 160 to 1019 metres.

The inhabitable water temperature ranges of the above-mentioned species of freshwater planarians which were found in Sapporo City and its adjacent district are follows: D.japonica $\left(2.0 \sim 19.8^{\circ} \mathrm{C}\right) ; P h$. vivida $\left(7.8 \sim 10.8^{\circ} \mathrm{C}\right) ; P h$. iwamai $\left(2.0 \sim 19.6^{\circ} \mathrm{C}\right)$; Pol. sapporo $\left(2.0 \sim 23.5^{\circ} \mathrm{C}\right)$; Pol. auriculata $\left(4.5 \sim 15.7^{\circ} \mathrm{C}\right)$; Den. locteus $\left(2.0 \sim 19.6^{\circ} \mathrm{C}\right)$; Den.ezensis $\left(2.0 \sim 19.6^{\circ} \mathrm{C}\right)$.

The type of the vertical distribution in the area surveyed is shown as JSVSVA (Ashiribetsu River) or JS-SA (the other district). The typical type of the vertical distribution in South and Central Hokkaidô is shown as JSV-SVA-VA-A (cf. KaWAKaTSU 1965, Table I). It seems that the types JSV-SVA and JS-SA are the part of the original type.

（著省：山田達也，北海道名寄高等学校，名奇市；Tatsuya YAMADA，Nayoro High School, Nayoro, Hokkaidô. 川勝正治, 藤女子大学生物学教室, 札㡌市；Masaharu KaWAKaTSU, Biological Laboratory, Fuji Women's College, Sapporo, Hokkaidô) 